\title{
Effects of trimetazidine in patients with severe chronic heart failure with reduced left ventricular ejection fraction: A prospective, randomized, open-label, cross-over study
}

\author{
Michał Bohdan ${ }^{1}$, Iwona Stopczyńska ${ }^{1}$, Piotr Wiśniewski ${ }^{2}$, \\ Joanna Moryśs ${ }^{3}$, Piotr Niedoszytko ${ }^{4}$, Marcin Gruchała ${ }^{1}$ \\ ${ }^{1}$ First Department of Cardiology, Medical University of Gdansk, Poland \\ ${ }^{2}$ Department of Endocrinology and Internal Diseases, Medical University of Gdansk, Poland \\ ${ }^{3}$ Department of Clinical Psychology, Medical University of Gdansk, Poland \\ ${ }^{4}$ Department of Rehabilitation Medicine, Medical University of Gdansk, Poland
}

\begin{abstract}
Background: Trimetazidine (TMZ) modulates cardiac metabolism, but its use in heart failure remains controversial. The aim of the study was to evaluate the effects of TMZ on exercise capacity, left ventricular ejection fraction (LVEF), mortality, and quality of life in stable patients with heart failure with reduced left ventricular ejection fraction (HFrEF).

Methods: Forty-five patients with stable advanced HFrEF treated with optimal medical therapy were randomized in a prospective, single-center, open-label, cross-over study of TMZ (35 mg b.i.d.) on top of standard medical therapy or standard pharmacotherapy for two periods of 30 days and one period of 6 months. Initially and at the end of each period all patients underwent the following: exercise testing, six-minute walk test (6MWT), two-dimensional-echocardiography, and quality of life assessment.

Results: The mean age of patients was $58.2 \pm 10.6$ years. Etiology of HFrEF was ischemic in $66.6 \%$ of patients. After 6 months no significant changes were observed in either group with regards to peak $V_{2}$ uptake, 6MWT, LVEF, or quality of life. TMZ had no effect on mortality or cardiovascular events. Conclusions: The additional use of TMZ on top of standard medical therapy in stable advanced HFrEF patients was not associated with significant changes in mortality, exercise capacity, LVEF, or quality of life. (Cardiol J 2022; 29, 4: 627-636)
\end{abstract}

Key words: trimetazidine, heart failure, cardiac metabolism, exercise capacity, echocardiography, prognosis

\section{Introduction}

Chronic heart failure (CHF) is one of the major challenges for healthcare systems in developed countries. Recently, the prevalence of CHF has increased from 5.7 to 6.5 million in Americans aged $\geq 20$ years [1]. Despite improvements in CHF therapy, the prognosis is poor, with 5-year survival reaching $61 \%$ in patients with $\mathrm{CHF}$ after myocardial infarction [2]. It has been shown that CHF is a syndrome characterized by metabolic abnormalities in the myocardium that lead to energy starvation [3]. Progression of heart failure is associated with the decrease of free fatty acid beta-oxidation

Address for correspondence: Michał Bohdan, MD, PhD, First Department of Cardiology, Medical University of Gdansk, ul. Dębinki 7, 80-952 Gdańsk, Poland, tel: +48 5834925 00, fax: +48 58349 12 01, e-mail: michal.bohdan@gumed.edu.pl Received: 20.09.2019 Accepted: 13.10.2020 Early publication date: 9.11.2020

This article is available in open access under Creative Common Attribution-Non-Commercial-No Derivatives 4.0 International (CC BY-NC-ND 4.0) license, allowing to download articles and share them with others as long as they credit the authors and the publisher, but without permission to change them in any way or use them commercially. 


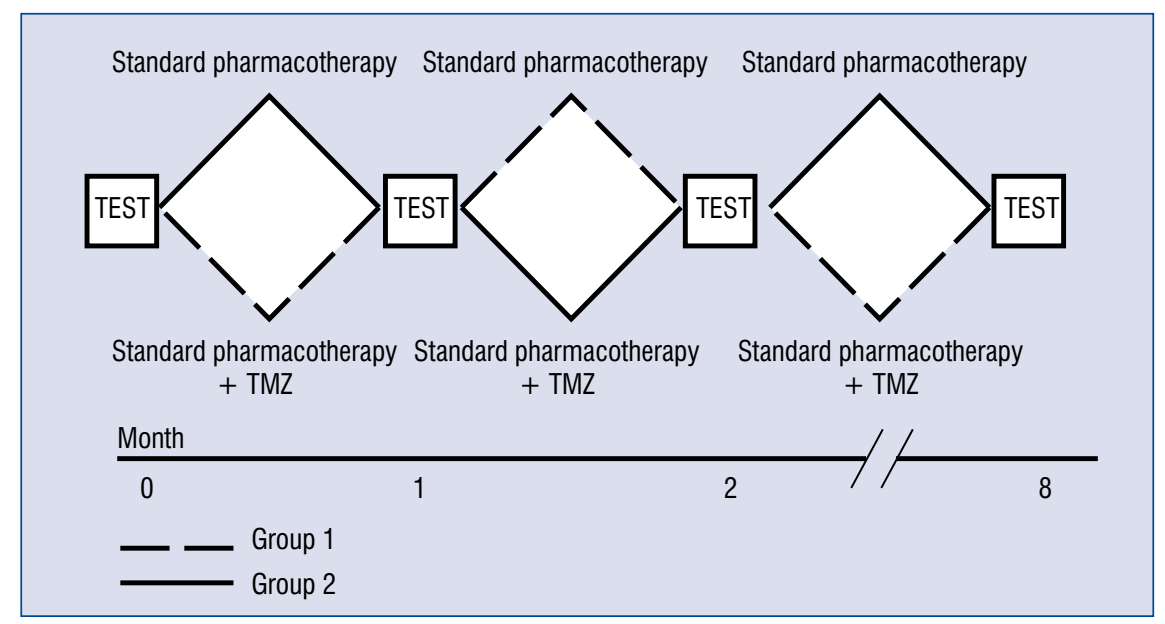

Figure 1. Study design. Standard pharmacotherapy = beta-blocker and angiotensin converting enzyme inhibitor or angiotensin receptor blocker and aldosterone blocker, if not contraindicated; TMZ — trimetazidine.

and promotion of glucose oxidation [3]. Metabolic alterations that occur in $\mathrm{CHF}$ mandate the potential use of metabolic modulators.

Trimetazidine (TMZ) has been evaluated in randomized trials and several meta-analyses in CHF patients. It has been observed that $\mathrm{TMZ}$ on top of standard pharmacotherapy reduces morbidity and mortality in patients with chronic heart failure with reduced left ventricular ejection fraction (HFrEF) [4-8]. Moreover, some studies suggest that TMZ may reduce the symptoms in New York Heart Association (NYHA) classification and increase the exercise duration in $\mathrm{CHF}[9,10]$. Some studies also indicate that TMZ may improve cardiopulmonary stress testing results and six-minute walk test (6MWT) distance [11, 12].

The available results of TMZ in CHF patients were derived mainly from retrospective analyses and small studies. There has been only one study assessing the effects of TMZ on cardiopulmonary stress testing and echocardiography in patients with nonischemic CHF [13]. Moreover, the data on beneficial role of $\mathrm{TMZ}$ in $\mathrm{CHF}$ are conflicting [13]. There are insufficient data from prospective analyses to support the use of TMZ in HFrEF. The aim of the study was to evaluate the effects of TMZ on exercise capacity, left ventricular ejection fraction (LVEF), cardiovascular mortality, and quality of life in CHF patients.

\section{Methods}

Patients were randomized to TMZ (35 $\mathrm{mg}$ b.i.d.) on top of medical therapy for 1 month fol- lowed by medical therapy alone for another month and then TMZ for 6 months (Group 1) and to medical therapy for 1 month followed by additional TMZ for another month and then medical therapy without TMZ for 6 months (Group 2) according to a computer-generated random list (Fig. 1) (Research randomizer, https://www.randomizer.org/). A wash-out period of 1 month was chosen to avoid any potential effect of TMZ on heart function after $\mathrm{TMZ}$ cessation. The primary endpoint of the study was change in mean LVEF. Secondary endpoints included changes in exercise capacity and quality of life. Inclusion criteria were as follows: 1 ) ischemic or nonischemic $\mathrm{CHF}$ for at least 1 year prior to randomization; 2) LVEF $\leq 35 \%$ evaluated in two-dimensional (2D) echocardiography at the index visit; 3) at least one documented CHF exacerbation within 12 months prior to randomization; 4) stable course of CHF with NYHA class II or III, defined as no exacerbation of CHF symptoms and/or no modifications of treatment for at least 3 months prior to randomization; and 5) age $\geq 18$ years. Exclusion criteria were as follows: 1) primary valvular disease; 2) neurological disorders; 3 ) severe kidney disease, with estimated glomerular filtration rate (eGFR) $<30 \mathrm{~mL} / \mathrm{kg} / \mathrm{min}$; 4) frailty syndrome; 5) presence of coronary lesions suitable for revascularization; 6) alcohol abuse; and 7) pregnancy.

Initially and during each visit cardiopulmonary stress testing (Medisoft Ergocard, Belgium) and $6 \mathrm{MWT}$ were performed in all patients. Symptom severity was assessed with the use of NYHA classification. LVEF was calculated automatically and using biplane Simpson's method in 2D 
echocardiography (Vivid 6, GE Healthcare, USA). The MacNew heart disease health-related quality of life questionnaire was used to measure quality of life. Blood samples were also taken for further analyses. Adverse events associated with $\mathrm{TMZ}$ were monitored by a safety committee. The study was approved by Local Ethics Committee (NKBBN/346/2012).

\section{Statistical analysis}

Continuous variables are presented as mean \pm standard deviation and categoric variables as percentages (\%). All statistical analyses were performed with STATA, version 13.1 (Statacorp, Texas, USA). Baseline parameters in two groups were compared by two-sample t-test or Mann-Whitney test. In order to assess the effects of $\mathrm{TMZ}$ in the study group mixed models with random effects analysis was applied. To investigate the possible treatment, carry-over, sequence, and period effects, the 'pkcross' function in STATA software was used.

The results of the analyses are presented as changes in values of specific parameters at various time points in both groups.

In order to evaluate the impact of TMZ on survival a Kaplan-Meier estimator and log-rank test to make comparisons between groups were applied. The effect of TMZ on survival and cardiovascular $(\mathrm{CV})$ risk (CV hospitalization, implantable cardioverter-defibrillator [ICD] appropriate intervention(s), CV death) was assessed using a discreet-time hazard model. The significance level was set at $\mathrm{p} \leq 0.05$.

Power calculation was based on a paired t-test assuming a two-sided level of significance $\alpha=0.05$, power $1-\beta=0.80$. For the effect size calculation we assumed an expected mean LVEF change of $5 \%$ and a standard deviation of $8 \%$ in changes in LVEF from baseline to 6 months after treatment with the required sample size of $n=20$. To compensate for potential drop-out, we increased the total number of patients for this study to $n=45$.

\section{Results}

Forty-five patients with HFrEF were recruited in a prospective, single-center, open-label, cross-over study. All patients received standard pharmacotherapy for at least 6 months prior to randomization with $\beta$-blocker, angiotensin-converting enzyme inhibitor (ACEI) or angiotensin II receptor blocker (ARB), aldosteron blocker and diuretics, digoxin, and ivabradine were indicated. The mean age of study group was $58.2 \pm 10.6$ years. The majority of patients were male $(n=43,95.6 \%)$. There were no significant differences in basal characteristics in both groups except creatinine level (Table 1). Visits number 2,3 , and 4 were completed by $95.3 \%$, $86.7 \%$, and $73.3 \%$ of patients, respectively. Five patients were lost to follow-up. One patient was diagnosed with intracranial aneurysm and was referred to surgery, while 3 patients had $\mathrm{CHF}$ exacerbation and were not able to complete visit 4 . Three patients died due to $\mathrm{CV}$ reasons, and 19 patients had $22 \mathrm{CV}$ events (hospitalizations due to $\mathrm{CV}$ reasons, ICD intervention due to ventricular tachycardia). One patient experienced gastro-intestinal side effects that were attributed to TMZ.

\section{Exercise capacity}

Additional use of TMZ had no effect on peak oxygen consumption $\left(\mathrm{VO}_{2}\right.$ peak) and $\mathrm{VO}_{2}$ at the anaerobic threshold in both groups (Fig. 2A, B). Reduction of slope of minute ventilation versus carbon dioxide production (VE/ $\mathrm{VCO}_{2}$ slope) after 1 -month treatment with TMZ in Group 1 was observed $(47.2 \pm 2.4$ vs. $40.9 \pm 2.5$ at 1 month, $\mathrm{p}=0.07$; Fig. $2 \mathrm{C}$ ). No effect of TMZ on 6MWT distance was noted in either group (Fig. 2D). There was a significant reduction in NYHA classification at visit 2 in Group 2, and a similar tendency was observed in Group 1 at visit 3 (2.4 \pm 0.1 vs. $2.0 \pm 0.1$, $\mathrm{p}<0.01$ and $2.4 \pm 0.1$ vs. $2.1 \pm 0.1$, respectively). In addition, patients in Group 2 at visit 4 experienced a significant increase in symptom severity in NYHA class $(2.1 \pm 0.1$ vs. $2.4 \pm 0.1$, $\mathrm{p}<0.05$; Fig. 3D).

\section{Echocardiography}

Patients in Group 1 at visit 4 had a tendency towards LVEF increase $(24.6 \pm 1.4 \%$ vs. $26.7 \pm 1.5 \%$, $\mathrm{p}=0.059)$. Moreover, no significant effect of TMZ on left ventricular end-diastolic diameter (LVEDD) and left ventricular end-systolic diameter (LVESD) was found. Patients from Group 2 at visit 2 had significant increase in LVESD $(60.0 \pm 1.8 \mathrm{~mm}$ vs. $64.7 \pm 1.9 \mathrm{~mm}, \mathrm{p}<0.05)$. Interestingly, this effect in Group 2 was not confirmed during the following 6 months of observation on standard pharmacotherapy alone (Fig. 3A-C).

\section{Laboratory evaluation}

There were no differences in B-type natriuretic peptide (BNP) level at various time points in both groups. A significant rise in C-reactive protein (CRP) level was observed in patients in Group 1 
Table 1. Baseline characteristics.

\begin{tabular}{|c|c|c|c|}
\hline & Group I (n = 22) & Group II (n = 23) & $\mathbf{P}$ \\
\hline Age [years] & $59 \pm 9.6$ & $57.3 \pm 11.6$ & NS \\
\hline Gender, male & $22(48.9 \%)$ & $21(46.7 \%)$ & NS \\
\hline CHF duration [years] & $3.5 \pm 3.13$ & $3.17 \pm 1.72$ & NS \\
\hline \multicolumn{4}{|l|}{ CHF etiology: } \\
\hline Ischemic & $15(33.3 \%)$ & $15(33.3 \%)$ & NS \\
\hline Nonischemic & $7(15.6 \%)$ & $8(17.8 \%)$ & NS \\
\hline \multicolumn{4}{|l|}{ Concomitant diseases: } \\
\hline Diabetes & $3(6.7 \%)$ & $8(17.8 \%)$ & NS \\
\hline Hypertension & $11(24.4 \%)$ & $12(26.7 \%)$ & NS \\
\hline Chronic kidney disease & $8(18.2 \%)$ & $6(13.6 \%)$ & NS \\
\hline COPD & $3(6.8 \%)$ & $2(4.6 \%)$ & NS \\
\hline CRT & $7(15.9 \%)$ & $3(6.8 \%)$ & NS \\
\hline NYHA (mean \pm SD) & $2.3 \pm 0.5$ & $2.4 \pm 0.5$ & NS \\
\hline NYHA II & $16(35.6 \%)$ & $13(28.9 \%)$ & NS \\
\hline NYHA III & $6(13.3 \%)$ & $10(22.2 \%)$ & NS \\
\hline BMI $\left[\mathrm{kg} / \mathrm{m}^{2}\right]$ & $27.5 \pm 5.1$ & $28.8 \pm 3.7$ & NS \\
\hline $\mathrm{BNP}[\mathrm{pg} / \mathrm{mL}]$ & $694.2 \pm 746.8$ & $575.0 \pm 502.5$ & NS \\
\hline Hemoglobin $[\mathrm{g} / \mathrm{L}]$ & $13.9 \pm 1.5$ & $14.5 \pm 1.5$ & NS \\
\hline Red cell width & $15.1 \pm 1.7$ & $15.3 \pm 2.1$ & NS \\
\hline Sodium $[\mathrm{mmol} / \mathrm{L}]$ & $138.5 \pm 2.4$ & $137.3 \pm 3.2$ & NS \\
\hline hs-CRP [mg/L] & $2.9 \pm 1.9$ & $3.2 \pm 2.5$ & NS \\
\hline Creatinine $[\mathrm{mg} / \mathrm{dL}]$ & $1.3 \pm 0.3$ & $1.1 \pm 0.2$ & $<0.05$ \\
\hline eGFR $\left[\mathrm{mL} / \mathrm{kg} / 1.73 \mathrm{~m}^{2}\right]$ & $63.6 \pm 18.7$ & $72.3 \pm 16.5$ & NS \\
\hline Sinus rhythm & $10(24.4 \%)$ & $16(39 \%)$ & NS \\
\hline LVEF [\%] & $23.6 \pm 5.9$ & $22.5 \pm 6.7$ & NS \\
\hline VO2 peak $[\mathrm{mL} / \mathrm{kg} / \mathrm{min}]$ & $11.7 \pm 3.7$ & $12.3 \pm 3.9$ & NS \\
\hline VO2 (AT) [mL/kg/min] & $8.8 \pm 2.6$ & $9.2 \pm 1.9$ & NS \\
\hline VE/VCO2 slope & $46.7 \pm 12.9$ & $40.5 \pm 10.9$ & NS \\
\hline $6 \mathrm{MWT}(\mathrm{m})$ & $392.7 \pm 108.4$ & $377.7 \pm 91.3$ & NS \\
\hline \multicolumn{4}{|l|}{ Seattle Heart Failure Model: } \\
\hline Mortality 1 year [\%] & $6.4 \pm 5.7$ & $6.1 \pm 4.9$ & NS \\
\hline Mortality 2 years [\%] & $12.2 \pm 10.3$ & $11.7 \pm 9.3$ & NS \\
\hline Mortality 5 years [\%] & $28.9 \pm 20.3$ & $27.9 \pm 19.6$ & NS \\
\hline Mean life expectancy [years] & $11.6 \pm 6.5$ & $11.8 \pm 6.6$ & NS \\
\hline Beta-blocker & $22(100 \%)$ & $23(100 \%)$ & NS \\
\hline MRA & $19(86.4 \%)$ & $23(100 \%)$ & NS \\
\hline ACEI & $20(90.9 \%)$ & $20(86.9 \%)$ & NS \\
\hline ARB & $2(9.1 \%)$ & $3(13.04 \%)$ & NS \\
\hline
\end{tabular}

ACEI - angiotensin converting enzyme inhibitor; ARB — angiotensin receptor blocker; BMI — body mass index; BNP — B-type natriuretic peptide; CHF — chronic heart failure; COPD — chronic obstructive pulmonary disease; CRT — cardiac resynchronization therapy; eGFR estimated glomerular filtration rate; hs-CRP — high-sensitivity C-reactive protein; LVEF — left ventricular ejection fraction; MRA - mineralocorticoid receptor antagonist; NYHA - New York Heart Association; VO2 peak — peak oxygen uptake; 6MWT — six-minute walk test

after 1 -month TMZ treatment $(2.5 \pm 1.2 \mathrm{mg} / \mathrm{L}$ vs. $6.4 \pm 1.2 \mathrm{mg} / \mathrm{L})$. Moreover, in Group 1 there was a tendency towards CRP reduction after a 1-month pe- riod without TMZ $(6.4 \pm 1.2 \mathrm{mg} / \mathrm{L}$ vs. $3.2 \pm 1.3 \mathrm{mg} /$ $/ \mathrm{L}, \mathrm{p}=0.071)$. No effects on CRP were found in a 6-month period with TMZ in Group 1 (Fig. 4A, B). 


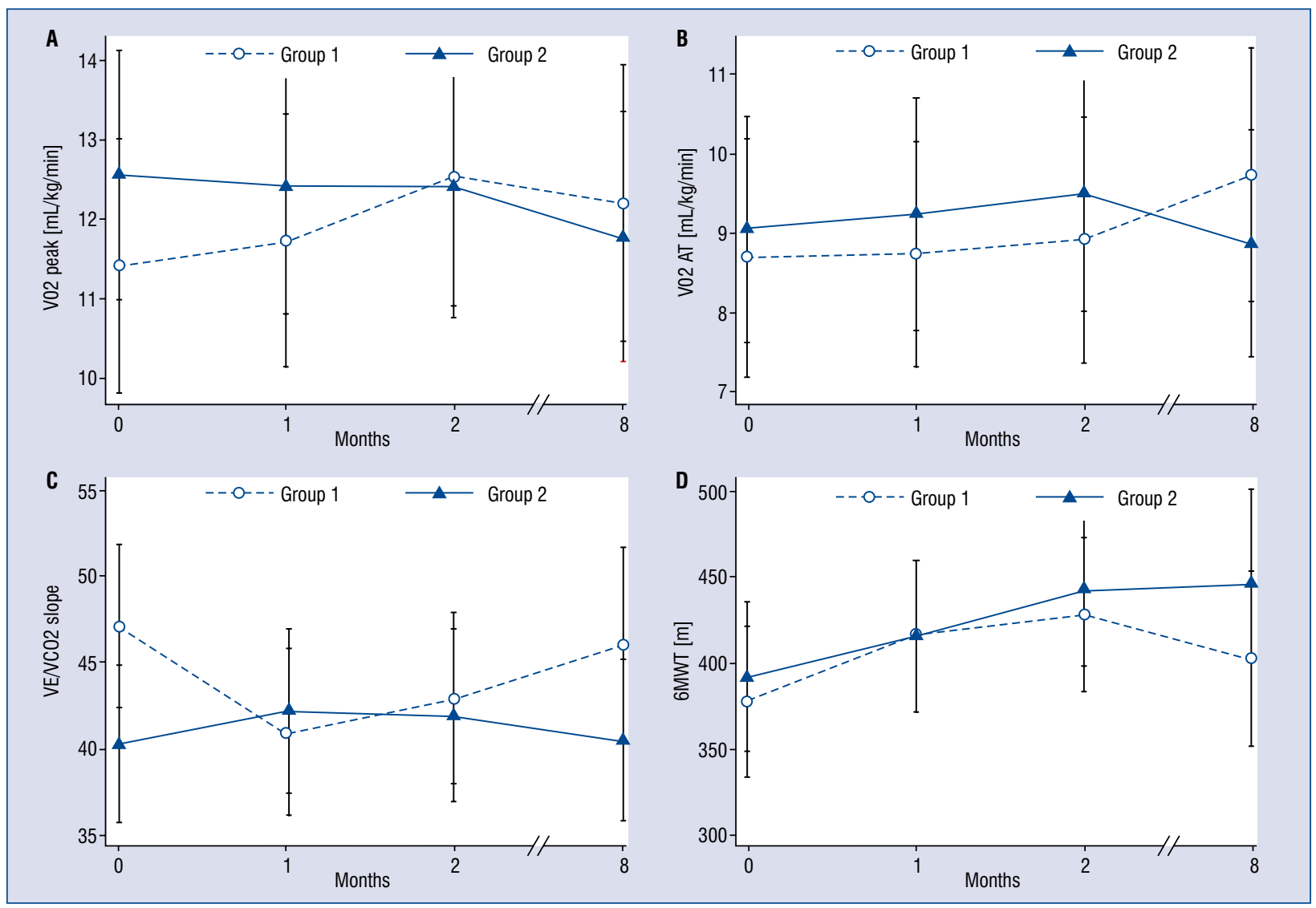

Figure 2. Peak oxygen consumption $\left(\mathrm{VO}_{2}\right.$ peak), $\mathrm{VO}_{2}$ in anaerobic threshold (AT), slope of minute ventilation versus carbon dioxide production (VE/ $\mathrm{VCO}_{2}$ slope), and six-minute walk test $(6 \mathrm{MWT})$ values in both groups at various time points.

\section{Mortality and cardiovascular events}

No impact on CV mortality of TMZ was observed (odds ratio [OR]: $2.22,95 \%$ confidence interval [CI] 0.2-24.5). In addition, TMZ was not associated with any significant effects on CV events, including CV deaths (OR 0.5, 95\% CI 0.2-1.2; Fig. 4C, D).

\section{Health-related quality of life}

Patients in Group 1 had significant deterioration of quality of life during 6-month TMZ treatment in MacNew Global ( $5.5 \pm 0.2$ points vs. $5.1 \pm$ \pm 0.2 points, $\mathrm{p}<0.05)$, MacNew Physical $(5.0 \pm$ \pm 0.2 points vs. $4.6 \pm 0.3$ points, $\mathrm{p}<0.04)$, MacNew Social $(5.5 \pm 0.2$ points vs. $4.9 \pm 0.2$ points, $\mathrm{p}<$ $<0.05$ ), and a tendency towards decreased MacNew Emotional $(5.9 \pm 0.2$ points vs. $5.5 \pm 0.2$ points, $\mathrm{p}=0.066$ ). Moreover, a significant decrease in MacNew Emotional after 6-month treatment with standard medical therapy was also noted in Group 2 $(5.7 \pm 0.2$ points vs. $5.3 \pm 0.2$ points, $\mathrm{p}<0.05$; Fig. 5A-D).
Analysis of patients who responded with

Patients, who experienced an increase in LVEF of at least $5 \%$ at any time due to $\mathrm{TMZ}$ administration in comparison to other patients had the following initially: significantly lower BNP level (262.3 \pm $\pm 282.7 \mathrm{pg} / \mathrm{mL}$ vs. $714.1 \pm 653.9 \mathrm{pg} / \mathrm{mL} ; \mathrm{p}<0.05)$, lower 1 -year and 2 -year mortality $(3.6 \pm 4.5 \%$ vs. $6.9 \pm 5.3 \% ; \mathrm{p}<0.05$; and $6.9 \pm 7.9 \%$ vs. $13.2 \pm$ $\pm 9.7 \%$, respectively; $\mathrm{p}<0.05$ ), and improved predicted life expectancy according to Seattle Heart Failure Model $(15.5 \pm 7.3$ years vs. $10.7 \pm 6.0$ years; $\mathrm{p}<0.05$ ). In addition, patients who had LVEF $\geq 5 \%$ during $\mathrm{TMZ}$ treatment in comparison to other patients had a tendency towards more frequent occurrence of diabetes mellitus or pre-diabetes and arterial hypertension ( $55.6 \%$ vs. $22.2 \%$; $\mathrm{p}=0.063$ and $77.8 \%$ vs. $44.4 \%, \mathrm{p}=0.077$, respectively), a tendency towards higher hemoglobin level (15.1 \pm $\pm 1.1 \mathrm{~g} / \mathrm{L}$ vs. $13.9 \pm 1.6 \mathrm{~g} / \mathrm{L}, \mathrm{p}=0.055)$, and a tendency towards lower red cell width value $(14.2 \pm$ \pm 1.4 vs. $15.4 \pm 1.9, \mathrm{p}=0.076)($ Table 2$)$. 


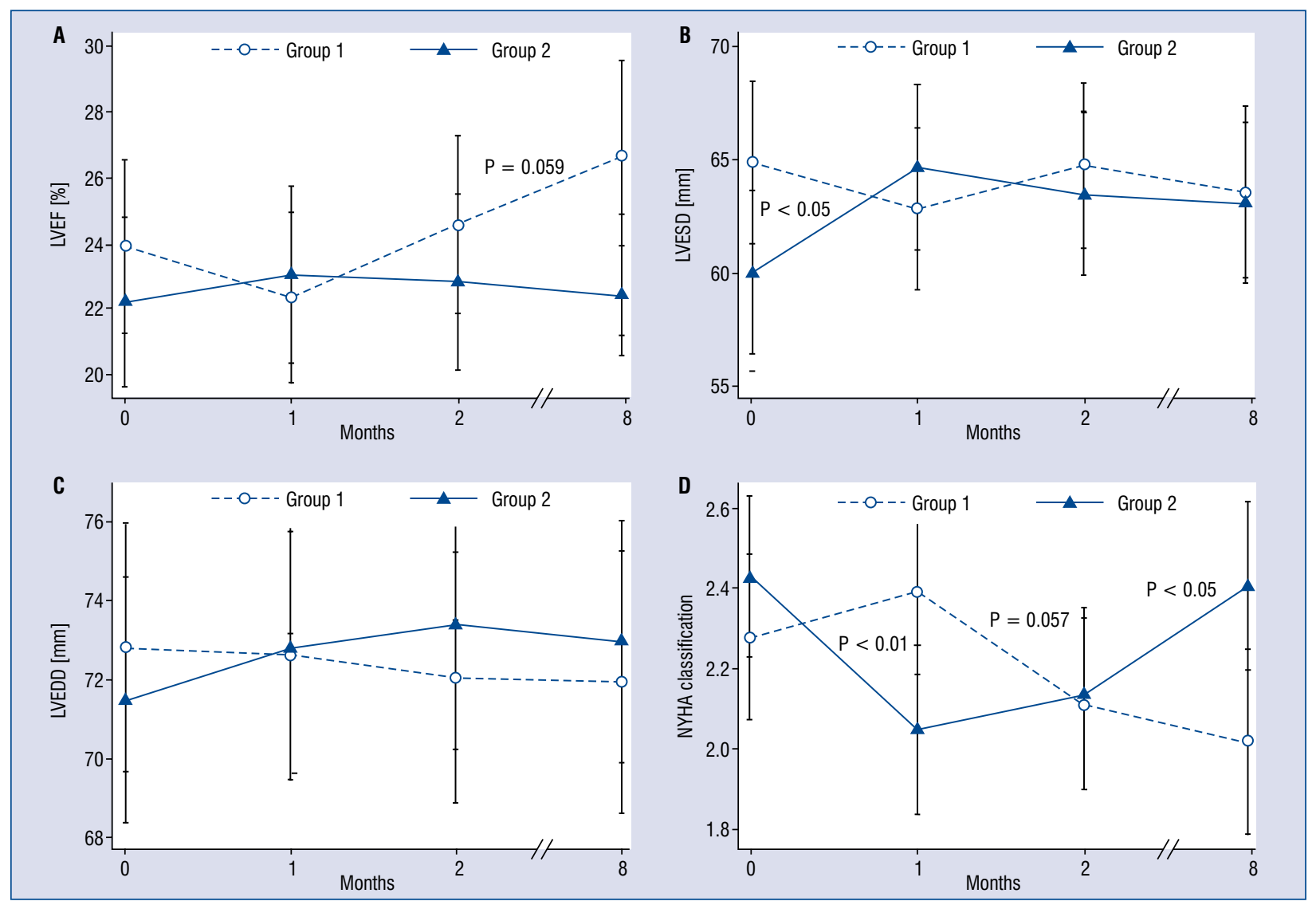

Figure 3. Left ventricular ejection fraction (LVEF), left ventricular end-systolic diameter (LVESD), left ventricular end-diastolic diameter (LVEDD), and New York Heart Association (NYHA) values in both groups at various time points.

\section{Discussion}

In this prospective, randomized, open-label study the use of TMZ on top of standard medical therapy in patients with severe HFrEF did not result in any significant improvement in exercise capacity, left ventricle contractility and left ventricular diameters, or quality of life. In addition, TMZ had no impact on CV events and CV mortality.

In recent years many studies have shown that TMZ has led to improvements in exercise capacity in CHF patients. Momen et al. [14] included in their study 98 patients with ischemic HFrEF. A significantly higher percentage of patients in NYHA class I and II was reported in the group that received TMZ for 6 months in comparison to patients receiving placebo $(22 \%$ vs. $8 \%, \mathrm{p}=0.03$ for NYHA I class and $56 \%$ vs. $34 \%, \mathrm{p}=0.01$ for NYHA II class, respectively). Moreover, these effects were also reported in a study in patients with dilated cardiomyopathy, who were randomized to TMZ $20 \mathrm{mg}$ t.i.d. on top of standard CHF pharmacotherapy vs. standard CHF pharmacotherapy [10]. At 3 months, reduced NYHA class (from $2.25 \pm 0.5$ to $1.85 \pm 0.46, \mathrm{p}=0.001$ ) and increased 6MWT distance (from $349.8 \pm 89.6 \mathrm{~m}$ to $402.1 \pm 87.6 \mathrm{~m}, \mathrm{p}=0.001$ ) were observed in the group that received TMZ. In addition, a meta-analysis by Gao et al. [6] suggested that TMZ on top of standard pharmacotherapy resulted in reduced NYHA classification (weighted mean difference [WMD] $0.41,95 \%$ CI $0.51-0.31, \mathrm{p}<0.01$ ) and increased exercise duration (WMD $30.26 \mathrm{~s} ; 95 \%$ CI 8.77-51.75; $\mathrm{p}<0.01$ ). Our study results with regards to NYHA class and 6MWT were partly consistent with those of Di Napoli et al. [15], who reported no changes in NYHA class after 6 -month treatment with TMZ, but a significant improvement in exercise capacity in patients receiving TMZ was found. Another study included 60 patients with dilated cardiomyopathy, who were randomized to two groups: one received TMZ $35 \mathrm{mg}$ b.i.d. and the other was given placebo. At 6 months, no significant improvements with regards to NYHA class, $6 \mathrm{MWT}$, and $\mathrm{VO}_{2}$ peak in patients receiving $\mathrm{TM} Z$ were noted [13]. 


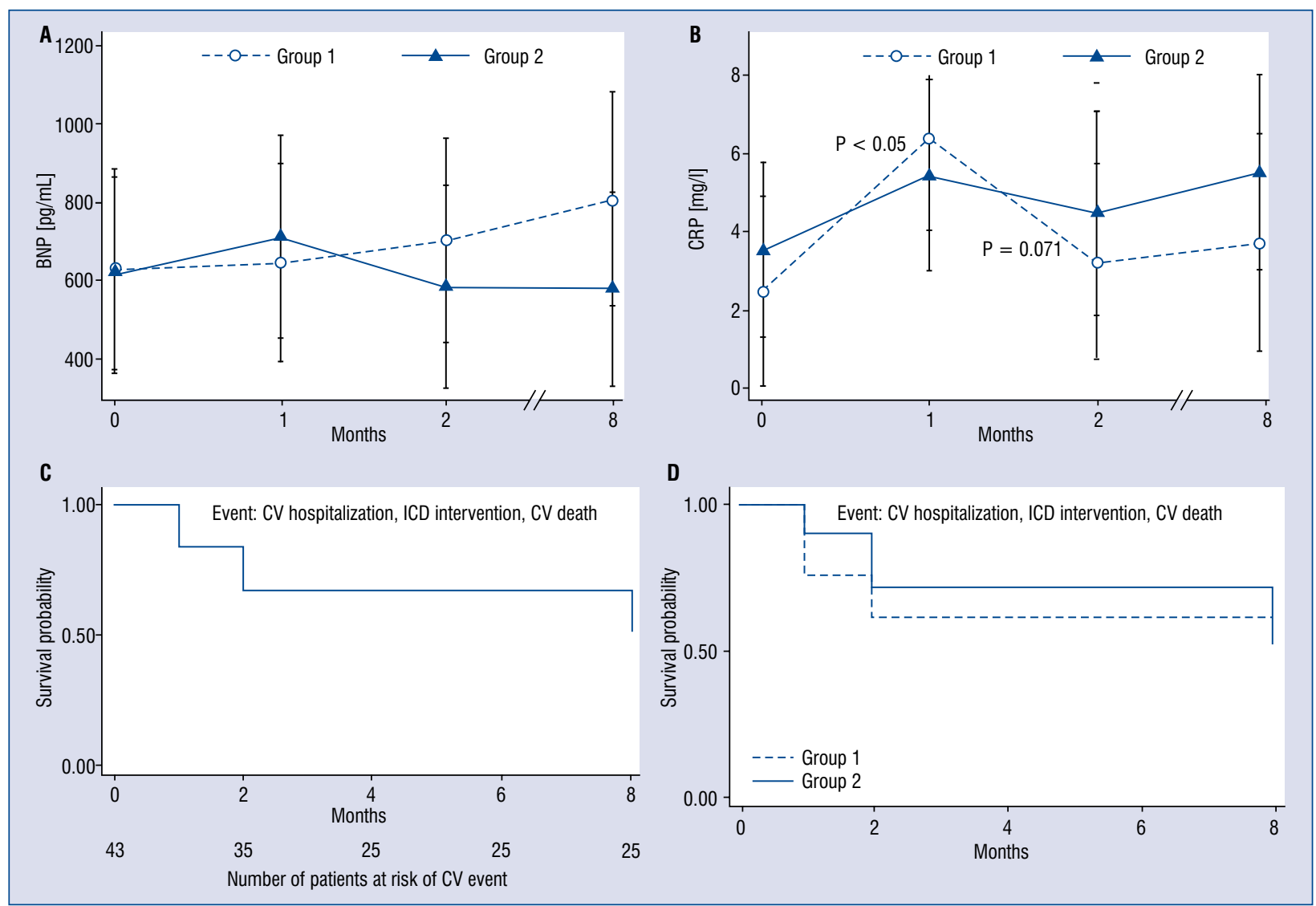

Figure 4. B-type natriuretic peptide (BNP), C-reactive protein (CRP) and cardiovascular (CV) events in both groups at various time points; ICD — implantable cardioverter defibrillator.

We found no significant effect of TMZ on cardiopulmonary stress testing. There are insufficient data in the literature concerning the effects of TMZ on cardiopulmonary stress testing in $\mathrm{CHF}$ patients, and 6MWT and total exercise duration (TED) were mainly used to assess the impact of TMZ on exercise capacity. Our study is therefore one of the few observations on TMZ effects with regards to cardiopulmonary stress testing. Zhao et al. [8] in a meta-analysis of studies including subgroup of patients with CHF and coronary artery disease reported a significant increase in TED (WMD of 50.01 [ $\mathrm{n}=214,95 \%$ CI 44.77-55.25, $\mathrm{p}<0.001])$. Interestingly, TMZ treatment was also associated with significant increase in $\mathrm{pVO}_{2}(\mathrm{n}=$ $=204$, WMD 2.41, 95\% CI 1.76-3.06, $\mathrm{p}<0.00001$ ), METS ( $\mathrm{n}=611$, WMD 1.33, 95\% CI 0.38-2.28, $\mathrm{p}=0.006)$, and 6-MWT $(\mathrm{n}=218$, WMD 62.46 , 95\% CI 35.86-89.05, $\mathrm{p}<0.00001)$ in patients with coronary disease [8]. In another meta-analysis, however, no significant effect of TMZ on TED was observed [4]. In our study the initially low $\mathrm{VO}_{2}$ peak values indicate that the study group had an advanced CHF. It cannot be excluded, therefore, that the lack of anticipated beneficial effects of TMZ with regards to cardiopulmonary parameters, 6MWT distance, and NYHA class may be associated with the severity of $\mathrm{CHF}$ and irreversible changes that occurred in myocardium.

Our study revealed a tendency towards LVEF increase in patients who received TMZ for 6 months. Moreover, patients who responded with $\mathrm{LVEF}$ increase $\geq 5 \%$ to TMZ treatment had initially lower BNP level, lower 1-year and 2-year mortality and higher life expectancy according to Seattle Heart Failure Model in comparison to patients without increase in $\mathrm{LVEF} \geq 5 \%$ during TMZ administration. This observation may indicate that there is a higher probability of LVEF improvement due to TMZ treatment in patients with less advanced CHF. In addition, there was a tendency towards higher incidence of diabetes or pre-diabetes and hypertension in patients with increased LVEF $\geq 5 \%$ in comparison to subjects without increased $\mathrm{LVEF} \geq 5 \%$ on TMZ. The results of studies the concerning TMZ effects in patients with CHF and 


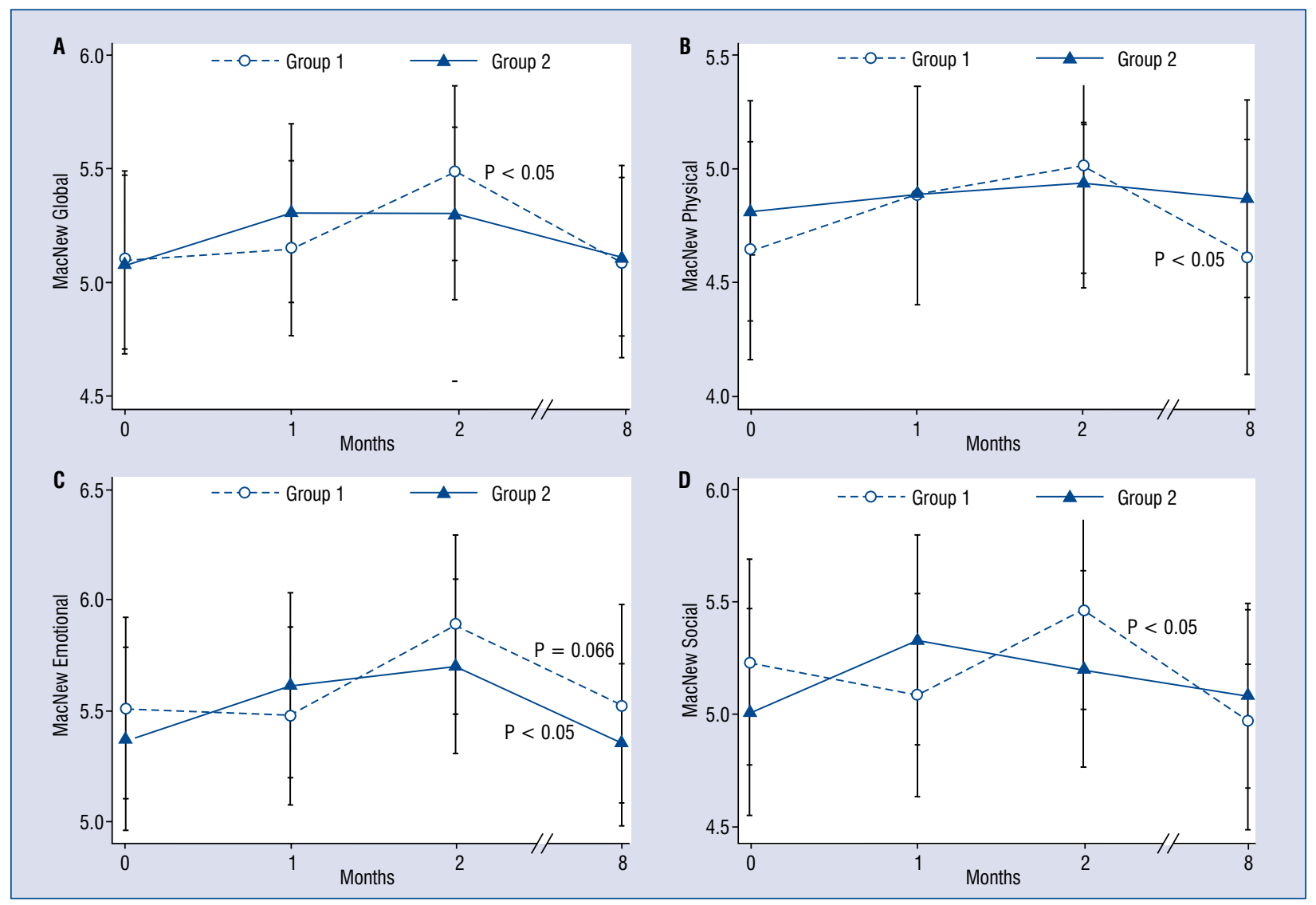

Figure 5. MacNew health-related quality of life.

diabetes are unclear. Thrainsdottir et al. [16] in a small group of ischemic CHF patients with diabetes found no effects of TMZ with regards to LVEF, while Gunes et al. [17] reported a significant correlation between $\mathrm{LVEF}$ rise during TMZ treatment and diabetes occurrence $(\mathrm{r}=0.524, \mathrm{p}<0.001)$.

The data concerning the effects of TMZ on left ventricular function are conflicting. The majority of available studies in CHF reported beneficial effects of TMZ on LVEF. Gao et al. [6] observed that TMZ treatment resulted in LVEF improvements both in ischemic and non-ischemic patients (WMD 7.37\%, 95\% CI 6.05-8.7, $\mathrm{p}<0.01$ and WMD 8.72\%, 95\% CI 5.51-11.92, $\mathrm{p}<0.01$, respectively). In addition, TMZ treatment was associated with significant left ventricular end-systolic volume (LVESV) reduction (WMD $10.37 \mathrm{~mL} ; 95 \%$ CI 15.46-5.29, p < 0.01) [6]. In other meta-analysis, a significant increase in LVEF (WMD 7.29\%, 95\% CI 6.49-8.09, p < 0.01), reduction of LVESV (WMD $-17.09 \mathrm{~mL}, 95 \% \mathrm{CI}$ -20.15 to $-14.04, \mathrm{p}<0.01$ ), and reduction of left ventricular end-diastolic volume (WMD $-11.24 \mathrm{~mL}$, $95 \%$ CI -14.06 to -8.42 , $\mathrm{p}<0.01$ ) was found. On the other hand, there were also studies that did not find any significant effects of TMZ on LVEF in CHF patients $[13,15]$.

We observed no significant effect of TMZ on $\mathrm{CV}$ events and mortality in patients with HFrEF. Meta-analyses and retrospective studies including larger numbers of participants provided data on the beneficial effect of TMZ in terms of mortality reduction. Grajek et al. [7] included 326 patients with $\mathrm{CHF}$ and reported significant mortality reduction in patients using TMZ (relative risk $[R R]=$ $=0.283, \mathrm{p}<0.0001$ ). Moreover, Fragasso et al. [18] analyzed the effect of TMZ on morbidity and mortality during 3-year follow-up. This study confirmed $11.3 \%$ improved global survival $(p=0.015)$ and $8.5 \%$ improved survival for CV death $(\mathrm{p}=0.05)$ in the TMZ group. Interestingly, the observed rate of hospitalization for $\mathrm{CV}$ causes was also reduced by $10.4 \%$ at 5 years $(\mathrm{p}<0.0005)$ with increased hospitalization-free survival of 7.8 months [18]. Other meta-analysis also corroborated that TMZ had a significant positive effect on mortality (RR $0.29,95 \%$ CI $0.17-0.49, \mathrm{p}<0.00001)$ and resulted 
Table 2. Comparison of patients with $\operatorname{LEF} \geq 5 \%$ and patients without $L V E F \geq 5 \%$ during trimetazidine treatment.

\begin{tabular}{|c|c|c|c|}
\hline Variable & $\Delta \mathrm{LVEF} \geq \mathbf{5} \%(\mathrm{n}=\mathbf{9})$ & $\Delta$ LVEF $<5 \%(n=36)$ & $\mathbf{P}$ \\
\hline Age [years] & $58.4 \pm 9.7$ & $58.4 \pm 10.9$ & NS \\
\hline Male & $9(100 \%)$ & $34(94.4 \%)$ & NS \\
\hline CHF duration [years] & $3 \pm 2.1$ & $3.4 \pm 2.6$ & NS \\
\hline Coronary artery disease & $5(55.6 \%)$ & $25(69.4 \%)$ & NS \\
\hline Diabetes or prediabetes & $5(55.6 \%)$ & $8(22.2 \%)$ & 0.063 \\
\hline Hypertension & $7(77.8 \%)$ & $16(44.4 \%)$ & 0.077 \\
\hline Chronic kidney disease & $3(33.3 \%)$ & $11(30.6 \%)$ & NS \\
\hline COPD & 0 & $5(13.9 \%)$ & NS \\
\hline CRT & $1(11.1 \%)$ & $9(25 \%)$ & NS \\
\hline NYHA II & $6(66.7 \%)$ & $23(63.9 \%)$ & NS \\
\hline NYHA III & $3(33.3 \%)$ & $13(36.1 \%)$ & NS \\
\hline $\mathrm{BMI}\left[\mathrm{kg} / \mathrm{m}^{2}\right]$ & $27.1 \pm 4.1$ & $27.9 \pm 4.5$ & NS \\
\hline BNP $[p g / m L]$ & $262.3 \pm 282.7$ & $714.1 \pm 653.9$ & 0.025 \\
\hline Hemoglobin $[\mathrm{g} / \mathrm{L}]$ & $15.1 \pm 1.1$ & $13.9 \pm 1.6$ & 0.055 \\
\hline Red cell width & $14.2 \pm 1.4$ & $15.4 \pm 1.9$ & 0.076 \\
\hline Sodium [mmol/L] & $137.2 \pm 3.2$ & $138 \pm 2.8$ & NS \\
\hline hs-CRP [mg/L] & $3.1 \pm 2.4$ & $3.1 \pm 2.2$ & NS \\
\hline Creatinine $[\mathrm{mg} / \mathrm{dL}]$ & $1.1 \pm 0.2$ & $1.2 \pm 0.3$ & NS \\
\hline eGFR $\left[\mathrm{mL} / \mathrm{kg} / 1.73 \mathrm{~m}^{2}\right]$ & $76.8 \pm 18.4$ & $65.8 \pm 17.4$ & NS \\
\hline Initial $H R \leq 75 / \mathrm{min}$ & $4(44.4 \%)$ & $19(52.8 \%)$ & NS \\
\hline Sinus rhythm & $5(62.5 \%)$ & $21(61.8 \%)$ & NS \\
\hline Optimal pharmacotherapy & $4(44.4 \%)$ & $18(50 \%)$ & NS \\
\hline LVEF [\%] & $23.1 \pm 6.6$ & $23.1 \pm 6.4$ & NS \\
\hline LVEDD [mm] & $71.3 \pm 4.5$ & $72.6 \pm 8.9$ & NS \\
\hline LVESD [mm] & $61.8 \pm 5.9$ & $61.6 \pm 9.9$ & NS \\
\hline \multicolumn{4}{|l|}{ Seattle Heart Failure Model: } \\
\hline Mortality 1 year [\%] & $3.6 \pm 4.5$ & $6.9 \pm 5.3$ & 0.03 \\
\hline Mortality 2 years [\%] & $6.9 \pm 7.9$ & $13.2 \pm 9.7$ & 0.03 \\
\hline Mortality 5 years [\%] & $17.9 \pm 16.8$ & $31.0 \pm 19.7$ & NS \\
\hline Mean life expectancy (years) & $15.5 \pm 7.3$ & $10.7 \pm 6.0$ & 0.047 \\
\hline
\end{tabular}

$\mathrm{BMI}$ - body mass index; BNP — B-type natriuretic peptide; CHF — chronic heart failure; COPD — chronic obstructive pulmonary disease; CRP - C-reactive protein; CRT — cardiac resynchronization therapy; eGFR - estimated glomerular filtration rate; hs-CRP - high-sensitivity C-reactive protein; HR - heart rate, LVEDD - left ventricular end-diastolic diameter; LVEF — left ventricular ejection fraction; LVESD — left ventricular end-systolic diameter; NYHA — New York Heart Association

in reduction of $\mathrm{CV}$ events and hospitalizations $(\mathrm{RR}$ $0.42,95 \%$ CI $0.30-0.58, \mathrm{p}<0.00001)[6]$.

We observed no positive effect of TMZ on quality of life. The deterioration of quality of life in Group 1 after 6-month TMZ treatment may be a result of the patients' disappointment with the lack of anticipated beneficial effects of TMZ. Lack of improvements in exercise capacity and echocardiography may have led to emotional exhaustion. In addition, perceived exercise capacity deterioration during TMZ treatment may explain the significant reduction in the MacNew Physical subscale. The majority of studies evaluating TMZ in CHF reported beneficial effects of TMZ on quality of life with the use of visual-analogue scale [19-21]. Winter et al. [13], on the other hand, reported no beneficial effect of TMZ administration on quality of life.

\section{Limitations of the study}

The lack of a double-blind, placebo-controlled study and the relatively small sample size may be considered as limitations of the study. The exercise 
capacity assessment, however, was performed by using objective methods such as cardiopulmonary stress testing or 6MWT, and these results were also accompanied by echocardiography and laboratory tests. Moreover, the majority of studies that focused on TMZ in CHF were open-label and largely underpowered.

In addition, the study was conducted in the period 2012-2016. At that time sacubitril/valsartan (ARNI) was not available in Poland. Therefore, we were not able to test TMZ efficacy in patients receiving ARNI.

The study group was statistically efficient due to cross-over methodology. This is one of the few prospective, randomized, cross-over evaluations of TMZ in advanced HFrEF.

\section{Conclusions}

Trimetazidine on top of standard pharmacotherapy in $\mathrm{CHF}$ patients, irrespective of $\mathrm{CHF}$ etiology, did not lead to any beneficial effects on $\mathrm{CV}$ events, including mortality, it was not associated with beneficial effect in exercise capacity, and it had no positive effect on quality of life in stable patients with severe HFrEF. Presumably, patients with less advanced stage of CHF may have a better response to $T M Z$, resulting in left ventricle contractility improvement.

\section{Conflict of interest: None declared}

\section{References}

1. Benjamin EJ, Blaha MJ, Chiuve SE, et al. Heart Disease and Stroke Statistics-2017 Update: A Report From the American Heart Association. Circulation. 2017; 135(10): e146-e603, doi: 10.1161/CIR.0000000000000485, indexed in Pubmed: 28122885.

2. Gerber Y, Weston SA, Enriquez-Sarano M, et al. Mortality associated with heart failure after myocardial infarction: a contemporary community perspective. Circ Heart Fail. 2016; 9(1): e002460, doi: 10.1161/CIRCHEARTFAILURE.115.002460, indexed in Pubmed: 26699392.

3. Neubauer S. The failing heart--an engine out of fuel. N Engl J Med. 2007; 356(11): 1140-1151, doi: 10.1056/NEJMra063052, indexed in Pubmed: 17360992.

4. Zhou X, Chen J. Is treatment with trimetazidine beneficial in patients with chronic heart failure? PLoS One. 2014; 9(5): e94660, doi: 10.1371/journal.pone.0094660, indexed in Pubmed: 24797235.

5. Zhang $\mathrm{L}$, Lu Y, Jiang $\mathrm{H}$, et al. Additional use of trimetazidine in patients with chronic heart failure: a meta-analysis. J Am Coll Cardiol. 2012; 59(10): 913-922, doi: 10.1016/j.jacc.2011.11.027, indexed in Pubmed: 22381427.

6. Gao D, Ning N, Niu X, et al. Trimetazidine: a meta-analysis of randomised controlled trials in heart failure. Heart. 2011; 97(4): 278-286, doi: 10.1136/hrt.2010.208751, indexed in Pubmed: 21134903.
7. Grajek S, Michalak M. The effect of trimetazidine added to pharmacological treatment on all-cause mortality in patients with systolic heart failure. Cardiology. 2015; 131(1): 22-29, doi: 10.1159/000375288, indexed in Pubmed: 25832112.

8. Zhao Y, Peng L, Luo Y, et al. Trimetazidine improves exercise tolerance in patients with ischemic heart disease: a meta-analysis. Herz. 2016; 41(6): 514-522, doi: 10.1007/s00059-015-4392-2, indexed in Pubmed: 26668006.

9. Sisakian H, Torgomyan A, Barkhudaryan A. The effect of trimetazidine on left ventricular systolic function and physical tolerance in patients with ischaemic cardiomyopathy. Acta Cardiol. 2007; 62(5): 493-499, doi: 10.2143/AC.62.5.2023413, indexed in Pubmed: 17982971.

10. Jatain S, Kapoor A, Sinha A, et al. Metabolic manipulation in dilated cardiomyopathy: Assessing the role of trimetazidine. Indian Heart J. 2016; 68(6): 803-808, doi: 10.1016/j.ihj.2016.04.023, indexed in Pubmed: 27931551.

11. Di Napoli P, Di Giovanni P, Gaeta MA, et al. Trimetazidine and reduction in mortality and hospitalization in patients with ischemic dilated cardiomyopathy: a post hoc analysis of the Villa Pini d'Abruzzo Trimetazidine Trial. J Cardiovasc Pharmacol. 2007; 50(5): 585-589, doi: 10.1097/FJC.0b013e31814fa9cb, indexed in Pubmed: 18030070.

12. Belardinelli R, Lacalaprice F, Faccenda E, et al. Trimetazidine potentiates the effects of exercise training in patients with ischemic cardiomyopathy referred for cardiac rehabilitation. Eur J Cardiovasc Prev Rehabil. 2008; 15(5): 533-540, doi: 10.1097/ HJR.0b013e328304feec, indexed in Pubmed: 18797405.

13. Winter JL, Castro PF, Quintana JC, et al. Effects of trimetazidine in nonischemic heart failure: a randomized study. J Card Fail. 2014; 20(3): 149-154, doi: 10.1016/j.cardfail.2014.01.004, indexed in Pubmed: 24412523.

14. Momen A, Ali M, Karmakar PK, et al. Effects of sustainedrelease trimetazidine on chronically dysfunctional myocardium of ischemic dilated cardiomyopathy: Six months followup result. Indian Heart J. 2016; 68(6): 809-815, doi: 10.1016/j. ihj.2016.03.021, indexed in Pubmed: 27931552.

15. Di Napoli P, Di Giovanni P, Gaeta MA, et al. Beneficial effects of trimetazidine treatment on exercise tolerance and B-type natriuretic peptide and troponin $\mathrm{T}$ plasma levels in patients with stable ischemic cardiomyopathy. Am Heart J. 2007; 154(3): 602. e1-602.e5, doi: 10.1016/j.ahj.2007.06.033, indexed in Pubmed: 17719313.

16. Thrainsdottir IS, von Bibra H, Malmberg K, et al. Effects of trimetazidine on left ventricular function in patients with type 2 diabetes and heart failure. J Cardiovasc Pharmacol. 2004; 44(1): 101-108, doi: 10.1097/00005344-200407000-00014, indexed in Pubmed: 15175564.

17. Gunes Y, Guntekin U, Tuncer M, et al. Improved left and right ventricular functions with trimetazidine in patients with heart failure: a tissue Doppler study. Heart Vessels. 2009; 24(4): 277-282, doi: 10.1007/s00380-008-1118-x, indexed in Pubmed: 19626400.

18. Fragasso G, Rosano G, Baek SH, et al. Effect of partial fatty acid oxidation inhibition with trimetazidine on mortality and morbidity in heart failure: results from an international multicentre retrospective cohort study. Int J Cardiol. 2013; 163(3): 320-325, doi: 10.1016/j.ijcard.2012.09.123, indexed in Pubmed: 23073279.

19. Fragasso G, Salerno A, Lattuada G, et al. Effect of partial inhibition of fatty acid oxidation by trimetazidine on whole body energy metabolism in patients with chronic heart failure. Heart. 2011; 97(18): 1495-1500, doi: 10.1136/hrt.2011.226332, indexed in Pubmed: 21700755.

20. Marazzi G, Gebara O, Vitale C, et al. Effect of trimetazidine on quality of life in elderly patients with ischemic dilated cardiomyopathy. Adv Ther. 2009; 26(4): 455-461, doi: 10.1007/s12325-0090024-7, indexed in Pubmed: 19396409.

21. Vitale C, Wajngaten M, Sposato B, et al. Trimetazidine improves left ventricular function and quality of life in elderly patients with coronary artery disease. Eur Heart J. 2004; 25(20): 1814-1821, doi: 10.1016/j.ehj.2004.06.034, indexed in Pubmed: 15474696. 